\title{
HUBUNGAN ANTARA POWER OTOT LENGAN DAN KOORDINASI MATA TANGAN DENGAN AKURASI PASSING RUGBY UNIVERSITAS NEGERI JAKARTA
}

\author{
Ali Sangap \\ Iwan Barata dan Tirto Apriyanto
}

Fakultas Ilmu Olahraga Universitas Negeri Jakarta

Email: aliharahap4@gmail.com

iwanbarata@unj.ac.id dan tirtoapriyanto@unj.ac.id

\begin{abstract}
ABSTRAK
Tujuan penelitian ini adalah untuk mengetahui hubungan antara power otot lengan dan koordinasi mata tangan dengan akurasi passing rugby Universitas Negeri Jakarta. Penelitian ini menggunakan metode penelitian deskriptif dengan teknik korelasi. Populasi dalam penelitian ini adalah mahasiswa atlet rugby Unversitas Negeri Jakarta yang masih aktif berlatih, teknik pengambilan sampel menggunakan sampling jenuh, dimana semua anggota populasi digunakan sebagai sampel. Sampel dalam penelitian ini berjumlah 30 orang. Instrumen penelitian ini yaitu: (1) tes standing medicine ball side throw (2) tes lempar tangkap bola tenis (3) tes akurasi passing. Analisa data dalam penelitian ini menggunakan teknik korelasi dan regresi linier ganda dengan mencari persamaan regresi dan koefisien korelasi, berdasarkan analisis data penelitian diperoleh hasil 1. terdapat hubungan yang signifikan antara power otot lengan dengan akurasi passing rugby didukung oleh data penelitian, dan koefisien determinasi $=0.1664$ hal ini $16.64 \%$ akurasi passing dipengaruhi oleh power otot lengan. 2. terdapat hubungan yang signifikan antara koordinasi mata tangan dengan akurasi passing rugby didukung oleh data penelitian dan koefisien determinasi $=0,7378$ hal ini $73,78 \%$ akurasi passing dipengaruhi oleh koordinasi mata tangan. 3. hubungan yang signifikan antara power otot lengan dan koordinasi mata tangan secara bersama-sama dengan akurasi passing rugby didukung oleh data penelitian dan koefisien determinasi $=0.8082$ hal ini $80.82 \%$ akurasi passing dipengaruhi oleh power otot lengan dan koordinasi mata tangan.
\end{abstract}

\section{Kata Kunci: Power Otot Lengan, Koordinasi Mata Tangan, Akurasi Passing, Rugby}

\section{ABSTRACT}

The purpose of this study was to determine the relationship between arm muscle power and hand eye coordination with passing rugby accuracy at Jakarta State University. This study uses descriptive research methods with correlation techniques. The population in this study were students of the Jakarta State University rugby athlete who were still actively practicing, sampling techniques using saturated sampling, where all members of the population were used as samples. The sample in this study amounted to 30 people. The instruments of this study are: (1) standing medicine ball side throw test (2) tennis ball throwing test (3) passing accuracy test. Analysis of the data in this study uses correlation techniques and multiple linear regression by looking for regression equations and correlation coefficients, based on the analysis of research data obtained results 1 . there is a significant relationship between arm muscle power with rugby passing accuracy supported by research data, and the coefficient of determination = 0.1664 this $16.64 \%$ passing accuracy is affected by arm muscle power. 2. there is a significant relationship between hand eye coordination and rugby passing accuracy supported by research data and the coefficient of determination $=0.7378$ this is $73.78 \%$ passing accuracy is influenced by hand eye coordination. 3. Significant relationship between arm muscle power and 
hand eye coordination together with rugby passing accuracy is supported by research data and the coefficient of determination $=0.8082$ this is $80.82 \%$ passing accuracy is influenced by arm muscle power and hand eye coordination.

\section{Keywords: Arm Muscle Power, Hand Eye Coordination, Passing Accuracy, Rugby}

\section{PENDAHULUAN}

Rugby adalah permainan taktis dimana banyak pola yang direncanakan bermain, walaupun pemain yang memiliki keterampilan tinggi bisa mendominasi pada kondisi tertentu, seorang pemain rugby harus saling bergantung pada setiap anggota tim untuk menciptakan permainan yg solid dan membuat keputusan yang tepat. Dalam segala hal, keberhasilan tim tergantung pada pemain yang bekerja dalam kombinasi. Untuk menguasai bola dan menciptakan kesempatan membuat poin, anggota tim harus meningkatkan kemampuan mengoper dan menerima bola yang baik. Kemampuan ini saling melengkapi satu sama lainnya karena setiap bola yang dioper harus diterima dan dikontrol dengan baik.

Dalam permainan olahraga rugby dikenal berbagai teknik dasar. Teknik dasar dalam permainan ini adalah passing, tekel, ruck dan maul. Penguasaan teknik dasar rugby merupakan salah satu unsur yang turut menentukan menang atau kalahnya suatu tim didalam pertandingan, disamping unsur-unsur kondisi fisik, taktik dan mental. Dalam permainan olahraga rugby teknik dasar yang harus benar-benar dipelajari salah satu adalah teknik dasar passing. Apabila passing ini dilakukan tidak baik maka permainan tidak akan berjalan lancar, sehingga passing diperlukan keterampilan dan ketepatan yang baik agar permainan dapat berjalan dengan baik.

Peneliti melihat pada saat latihan maupun dalam situasi pertandingan, melakukan passing dengan baik dan tepat sasaran bukanlah hal mudah sesuai dengan keinginan, seringkali dalam melakukan passing bola datangnya lebih rendah, bola melambung tinggi, bahkan sering tidak sampai atau melenceng sehingga menghambat alur permainan.

Gerakan passing banyak didominasi oleh otot lengan. Oleh karena itu, unsur komponen fisik dalam melakukan gerakan passing dengan satu maupun dua tangan adalah kekuatan otot lengan. Gerakan dilakukan secara eksplosif. Maksudnya ketika melakukan passing kekuatan otot lengan yang dikerahkan secara maksimum dalam waktu sependekpendeknya untuk mengoper bola, atau disebut juga daya ledak/ power otot lengan.

Dalam bermain olahraga rugby sangatlah penting jika power otot lengan dan koordinasi mata tangan seimbang pada saat melakukan passing. Seseorang yang memiliki kualitas passing dengan tingkat kecepatan, kekuatan dan akurasi yang tinggi berarti memiliki tingkat koordinasi mata tangan yang baik dan bagus pada saat berlari mau berhenti untuk melakukan passing. Jika memiliki koordinasi mata tangan yang baik, maka seseorang tersebut akan mampu menemukan saat yang tepat untuk mengoper bola, begitu juga dalam memperhitungkan jarak dan tinggi sasaran sehingga passing yang dilakukan tepat dan terarah pada tempat yang dituju.

\section{POWER OTOT LENGAN}

Daya ledak adalah kekuatan jumlah pekerjaan yang bisa dilakukan selama waktu tertentu, kekuatan dan kecepatan sangat dibutuhkan agar tubuh seseorang dapat mencapai jumlah gerakan maksimum. Dayak ledak artinya hasil kerja setiap unit waktu.

Selanjutnya Bompa membagi daya ledak menjadi dua keterampilan yaitu daya ledak siklis dan daya ledak asiklis. Daya ledak asiklis biasanya digunakan pada olahraga yang gerakannya tidak sama, misalnya: lompat dan lempar dalam atletik, senam, loncat indah, anggar, bola voli, lay up basket dan lain-lain. Sedangkan daya ledak siklis digunakan pada olahraga yang gerakannya sama dan berulang-ulang, misalnya: lari cepat, berenang, bersepeda dan olahraga yang memerlukan kelincahan.

Berdasarkan pengertian power atau daya ledak yang telah dikemukakan, maka 
dapat disimpulkan bahwa daya ledak adalah kemampuan seseorang untuk menggerakkan kekuatan dengan cepat dalam waktu yang singkat untuk memberikan momentum yang paling baik pada tubuh atau objek dalam suatu gerakan eksplosif yang utuh untuk mencapai jarak atau sasaran yang diinginkan.

Penggerak utama dalam melakukan passing adalah otot lengan. Lengan merupakan bagian tubuh yang dominan dalam permainan rugby. Keberadaan lengan, baik proporsi maupun kemampuannya harus dimanfaatkan pada teknik yang benar untuk mendukung penguasaan teknik dasar passing dalam rugby. Ditinjau dari gerak anatomi, lengan merupakan anggota gerak atas. Sebagai anggota gerak atas lengan terdiri dari seluruh lengan, mulai dari lengan sampai ujung jari tangan.

Lengan sebagai bagian anggota tubuh atas, berfungsi untuk melakukan gerakan menarik, memegang atau menolakkan suatu benda. Lengan adalah salah satu anggota tubuh bagian atas yang disusun berdasarkan kerangka tulang dan sekelompok otot yang membungkusnya. Otot lengan yang bekerja dominan adalah otot tricep brachii, deltoids dan otot bicep brachii. Hal ini diperkuat oleh Hardianto Wibowo di dalam bukunya seperti dijelaskan sebagai berikut:

a. Otot lengan bagian atas: 1) otot-otot ventralis disebut otot bagian atas (fleksi), 2) otot dorsalis atau kedang (ekstensi); deltoids, bicep brachii, tricep brachii.

b. Otot lengan bagian bawah: otot-otot ventralis, otot-otot radialis, otot-otot dorsalis. Otot tangan:1) Otot-otot tenar/ ibu jari/ bagian lateral: abduktor pollisis bervis, opponeus pollisis, flexor pollisis, abduktor pillisis. 2) Otot-otot hipotenar/ kelingking/ bagian medial: palmoris brevis, abductor digiti quinti, flexor digiti quinti, opponeus digiti quinti. 3) Otot-otot bagian dalam lengan/ bagian tengah: lumbrikales, interossesi dorsalis, interossesi volaris.

Power otot lengan ditingkatkan melalui metode latihan yang terprogram dan terencana, hal ini penting dilihat pengaruh terhadap peningkatan power otot lengan. Banyak cara yang dapat dipakai untuk meningkatkan power, power merupakan perpaduan dari kekuatan dan kecepatan maka untuk meningkatkan power terlebih dahulu harus ditingkatkan adalah kekuatan. Secara umum defenisi kekuatan adalah menggunakan atau mengerahkan daya dalam mengatasi suatu tahanan atau hambatan tertentu. Kekuatan dibagi menjadi tiga golongan, yaitu:

1. Kekuatan Maksimal (Maximal Strength). Ada dua cara untuk menentukan kekuatan maksimal seseorang, pertama menggunakan metode 1RM (1 kali angkatan dengan beban maksimal). Kedua menggunakan metode angkatan dengan 10-12 pengulangan. Sedangkan latihan untuk meningkatkan kekuatan maksimal itu sendiri dapat ditingkatkan dengan dua cara, yaitu: 1) Hypertropie: menambah diameter otot menjadi lebih besar disebut hypertropie. 2) Koordinasi Intramuskular: memperbaiki kerjasama antar kelompok otot disebut juga memperbaiki koordinasi intramuskuler.

2. Daya tahan Kekuatan (Strength Endurance). Dalam penerapannya dilakukan dengan menggunakan metode yang paling sering dilakukan adalah cyrcuit training. Metode latihan ini menggunakan beban badan sendiri atau menggunakan beban badan luar, dilakukan secara simultan melakukan 6-10 jenis latihan dengan istirahat 30 detik antar latihan dan 3 menit antar set, denyut nadi masih berada dalam zona latihan.

3. Kekuatan yang Cepat (Power). Dalam penerapan dilapangan biasa menggunakan model latihan plyometric, contras training, namun pelatih harus hati-hati dalam menerapkan metode latihan plyometric. Harus ada tes awal untuk memastikan atlet siap melakukan latihan tersebut, dan atlet terhindar dari cidera latihan.

Jenis atau metode latihan pliometrik dan latihan beban dapat meningkatkan power otot lengan. Pyke mengutarakan bahwa latihan daya ledak otot (power) dikembangkan dari 
peningkatan kekuatan atau kecepatan melalui latihan berbeban.

Latihan pliometrik adalah latihan yang disusun untuk mendapatkan keuntungan dalam penyediaan dan penggunaan tenaga pada tubuh melalui lingkaran memanjang dan memendek, tergantung aktor fisiologis bahwa otot dapat lebih dipacu jika peregangan secara aktif sebelum menjadi pendek, hal ini akan meningkatkan toleransi otot, meningkatkan beban peregangan. Radcliffe dan Farentinos membagi bentuk latihan pliometrik menjadi tiga bagian, yaitu:

1. Latihan untuk otot pinggang dan tungkai, meliputi: loncat lambung, loncat-loncat, lompat, lompat langkah, langkah loncat, lompat pantul.

2. Latihan untuk otot togog, meliputi: melenting, mengayun, memutar, menekuk.

3. Latihan untuk angota gerak atas, meliputi: menekan, mengayun, melempar.

Power otot lengan merupakan suatu komponen kondisi fisik yang dapat menentukan hasil prestasi seseorang dalam bermain rugby. Pada teknik passing olahraga rugby power otot lengan ikut memberikan hubungan yang positif terhadap keberhasilan melakukan passing dalam upaya memberikan tekanan pada pihak lawan. Dimana pada saat melakukan passing, dilakukan dengan kekuatan maksimal dalam waktu yang singkat.

\section{KOORDINASI MATA TANGAN}

Kondisi fisik terdiri dari berbagai macam komponen fisik yang tidak dapat dipisahkan antara satu dengan yang lainnya, salah satu komponen fisik tersebut adalah koordinasi. Koordinasi adalah kemampuan seseorang, dalam mengintegrasikan gerakan-gerakan yang berbeda ke dalam suatu pola gerakan tunggal secara efektif.

Tentunya dengan tingkat koordinasi yang dimiliki seseorang, maka orang tersebut mampu melakukan gerakangerakan secara efisien, seperti dalam melakukan teknik passing dalam olahraga rugby, seorang pemain akan kelihatan mempunyai koordinasi gerak yang baik, bila ia dapat melihat kearah sasaran sambil memegang bola, kemudian melakukan passing dengan teknik yang benar dan luwes.

Don. R. Kirkendal koordinasi adalah keseluruhan dari pola gerak otot pada saat melakukan penampilan gerak yang pada akhirnya menghasilkan tingkat keterampilan seseorang. Seseorang yang koordinasi geraknya baik tidak akan mengalami kesulitan dalam melakukan berbagai macam bentuk keterampilan.

Pada dasarnya koordinasi dibedakan menjadi dua macam, yaitu koordinasi umum dan koordinasi khusus. Koordinasi umum merupakan kemampuan seluruh tubuh dalam menyesuaikan dan mengatur gerakan secara simultan pada saat melakukan suatu gerak. Misalnya koordinasi dalam keadaan atau situasi kalau kita sedang kehilangan keseimbangan, seperti karena jalan licin, mendarat setelah membuat salto atau mendarat dari rekstok, berhenti mendadak, atau dalam contact sports dimana tubrukan atau singgungan yang bisa menghilangkan keseimbangan badan tidak bisa dihindari dan sebagainya.

Koordinasi khusus merupakan koordinasi antar beberapa anggota badan, yaitu kemampuan untuk mengkoordinasikan gerak dari sejumlah anggota badan secara simultan. Pada umumnya setiap teknik cabang olahraga merupakan hasil dari perpaduan antara pandangan mata-tangan dan kerja kaki.

Rangkaian gerak yang terkoordinasi diperlikan jika seorang atlet melakukan gerak yang spesifik yang berkelanjutan baik dengan cepat maupun perlahan-lahan. Gerak harus selaras, berirama dan berurutan supaya terkoordinasi. Koordinasi antara mata tangan bercirikan keterpaduan informasi visual dengan anggota badan.

Kemampuan koordinasi mata tangan dalam teknik passing adalah yang dihasilkan oleh perpaduan antara gerak mata dan tangan saat melepas bola dan didukung oleh kemampuan intelegensi untuk melakukan pola gerak sesuai dengan situasi yang mempengaruhinya. Mata berfungsi untuk mempersepsikan sasaran berdasarkan jaraknya dan tingginya. Sedangkan tangan berfungsi untuk 
melakukan lemparan dan memperkirakan kekuatan yang digunakan agar hasil lemparan tepat sasaran.

\section{AKURASI PASSING RUGBY}

Akurasi merupakan kemampuan seseorang dalam mengendalikan atau mengarahkan bola terhadap suatu sasaran yang ditentukan. Untuk mencapainya seseorang harus berkonsentrasi penuh agar hasil yang diperoleh sesuai dengan perkiraan awal. Ketepatan adalah kemampuan seseorang untuk mengendalikan gerakan-gerakan terhadap suatu sasaran. Sasaran ini dapat merupakan suatu jarak atau obyek yang langsung harus dikenai dengan salah satu bagian tubuh.

Widiastuti ketepatan dapat berupa gerakan (performance) atau sebagai ketepatan hasil (result). Ketepatan berkaitan erat dengan kematangan system syaraf dalam memproses input atau stimulus yang datang dari luar, seperti tepat dalam menilai ruang dan waktu, tepat dalam mendistribusikan tenaga, tepat dalam mengkoordinasikan otot dan sebagainya.

Ketepatan adalah kemampuan seseorang untuk mengendalikan gerakgerak bebas terhadap suatu sasaran. Kemudian, J. Matakupan meninjau ketepatan dari suatu gerakan terbagi menjadi dua bagian :

1. Ketepatan dalam arti proses adalah ketepatan jalannya suatu gerakangerakan atau rangkaian gerak dilihat dari struktur gerakan dan sistematis gerakan.

2. Gerakan dalam arti produk hasil yang dicapai.

Dalam olahraga rugby akurasi passing tidak akan datang dengan sendirinya melainkan memerlukan latihanlatihan dengan di dorong oleh motivasi tinggi dan juga metode latihan yang tepat dalam dalam melatih akurasi passing. Menurut Suparno ada beberapa ciri-ciri dari latihan ketepatan yaitu: harus ada sasaran sebagai target, kecermatan dan ketelitian dalam melakukan gerakan, waktunya tertentu sesuai dengan peraturan dan adanya suatu penilai dalam latihan. Dalam pelaksanaannya perlu di perhatikan faktorfaktor penentu untuk pencapaian ketepatan, diantaranya adalah koordinasi, besar kecilnya sasaran, ketajaman indra, jarak sasaran, penguasaan teknik, cepat lambatnya gerakan, feeling dari atlet dan ketelitian, serta kuat lemahnya suatu gerakan.

Passing merupakan keterampilan dasar dalam permainan olahraga rugby, keterampilan ini merupakan keterampilan dasar yang dimiliki oleh pemain rugby agar dapat bermain dengan baik dan mempunyai rasa percaya diri. Passing membutuhkan banyak teknik yang sangat penting agar dapat tetap menguasai bola. Dengan passing yang baik, kamu akan dapat berlari ke ruang yang terbuka dan mengendalikan permainan saat membangun strategi penyerangan.

Teknik passing ini tidak akan dikuasi jika tidak dilatih dengan benar. Latihan yang rutin dapat sangat membantu dalam mengembangkan kemampuan para pemain dalam melakukan passing secara efektif dan efisien. Semakin banyak seseorang berlatih, maka semakin cepat ia menguasai teknik passing ini. Terdapat 3 jenis passing dalam bermain rugby, yaitu:

\section{Popp Pass}

Passing ini dilakukan oleh pemain kepada rekan satu tim yang berada pada posisi dekat atau dalam keadaan yang baik untuk menerima bola atau disebut juga dengan passing pendek. Popp pass bertujuan untuk mengoper bola pada ketinggian yang sama antara pengoper dan penerima bola, biasanya antara lutut dan pinggang. Passing ini boleh dilakukan dalam keadaan berlari maupun berhenti, yang penting adalah pengoper dan penerima bola saling mengerti.

\section{Dive Pass}

Passing ini dilakukan apabila bola berada diatas tanah pada posisi scrum, ruck, maul, atau lineout. Passing ini biasanya dilakukan oleh scrumhalf yang bertugas untuk menjemput bola dan melakukan passing kepada rekan satu tim sebagai sasaran. Dive Pass bertujuan untuk mengoper bola dengan jarak yang agak jauh dilakukan dengan mengoper bola sambil menerbangkan badannya pada sasaran pinggang atau lutut penerima bola. Setiap 
pemain harus dapat melakukan passing ini walaupun sering dilakukan oleh scrumhalf.

3. Spiral Pass

Spiral pass merupakan passing yang dilakukan untuk mengoper bola kepada rekan satu tim dengan satu maupun dua tangan. Passing dilakukan dengan cara memutar bola sehingga bergerak cepat, lurus dan terarah sehingga mudah ditangkap dan sulit dijangkau oleh lawan. Passing ini dilakukan dengan pemain mengayunkan tangan mengarah kebelakang dan tidak boleh mengoper bola mengarah kedepan. Spiral pass bertujuan untuk menguasai permainan dengan bergerak cepat agar memperoleh peluang untuk mencetak poin.

\section{KERANGKA BERPIKIR}

1. Hubungan antara Power Otot Lengan dengan Akurasi Passing Rugby

Soerang atlet rugby harus memiliki power otot lengan yang maksimal untuk dapat melakukan passing sebab hal ini diperlukan ketika akan melakukan passing jarak jauh atau operan yang cepat dan kuat. Otot yang bekerja dalam melakukan gerakan passing lebih dominan terjadi pada otot lengan. Dimana otot ini harus berada pada kualitas power yang baik untuk memaksimalkan umpan yang akurat.

Power otot lengan merupakan unsur yang sangat penting dalam keberhasilan passing karena pada saat akan melepas bola memerlukan gerakan tangan yang cepat dan kuat sehingga dapat menempatkan arah bola yang ingin dituju dan tidak dapat dihalau oleh pemain lawan. Dengan demikian dapat disimpulkan bahwa terdapat hubungan antara power otot lengan dengan akurasi passing rugby Universitas Negeri Jakarta.

2. Hubungan antara Koordinasi Mata Tangan dengan Akurasi Passing Rugby

Koordinasi mata tangan dalam passing rugby ditunjukkan pada saat pemain melakukan gerakantersebut. Dalam pelaksanaannya dibutuhkan koordinasi antara anggota badan yaitu koordinasi mata dan tangan. Mata berfungsi untuk mempersepsikan sasaran berdasarkan jaraknya dan tingginya. Sedangkan tangan berfungsi untuk melakukan lemparan dan memperkirakan kekuatan yang digunakan agar hasil lemparan tepat sasaran.

Passing merupakan salah satu teknik dasar dalam bermain rugby, pola gerakan passing ini membutuhkan koordinasi mata tangan yang baik. Sebab seorang pemain memiliki sedikit waktu untuk melihat sasaran sebelum melakukan passing. Untuk mencapai tujuan tersebut atlet harus mampu mengkombinasikan beberapa gerakan dengan urutan yang benar dan lancar agar tepat pada sasaran yang diinginkan.

3. Hubungan antara Power Otot Lengan dan Koordinasi Mata Tangan dengan Akurasi Passing Rugby

Power otot lengan dan koordinasi mata tangan adalah unsur komponen fisik yang sangat dominan dalam melakukan gerakan passing. Dengan adanya power otot lengan yang baik maka atlet rugby bebas mengoper bola sesuai dengan jarak yang diinginkan agar tidak dapat dihalau pemain lawan.

Dalam melakukan gerakan passing dibutuhkan kerjasama antara beberapa anggota badan agar gerakan menjadi lebih efektif efisien. Akurasi passing rugby memiliki gerakan yang kompleks dari mulai gerakan tangan dan koordinasi mata tangan.Dengan tingkat koordinasi yang dimiliki seseorang, maka orang tersebut mampu dalam melakukan gerakan-gerakan passing secara efisien dan tepat sasaran.

\section{METODE PENELITIAN}

Metode Penelitian ini merupakan penelitian deskriptif dengan pendekatan korelasi, adalah penelitian yang dirancang untuk mentukan tingkat hubungan variabelvariabel yang berbeda dalam suatu populasi.

Populasi dalam penelitian ini adalah mahasiswa atlet rugby Universitas Negeri Jakarta yang masih aktif berlatih sebanyak 30 orang. Dalam penelitian ini menggunakan teknik sampling jenuh, sampling jenuh adalah teknik penentuan sampel bila semua anggota populasi digunakan sebagai sampel. Sampel dalam penelitian ini berjumlah 30 orang atlet rugby yang berstatus sebagai mahasiswa yang aktif berlatih. 


\section{HASIL PENELITIAN}

Deskripsi data yang dimaksudkan adalah hasil penelitian yang disajikan dalam bentuk penyajian data yang sesuai dengan hasil pengukuran yang dilakukan sebelumnya. Pada penelitian ini data diperoleh dengan melakukan tes dan pengukuran secara langsung kepada responden mengenai Hubungan Antara Power Otot Lengan dan Koordinasi Mata Tangan dengan Akurasi Passing Rugby yang disajikan pada tabel berikut ini:

Tabel 1. Deskripsi Data Penelitian

\begin{tabular}{llll}
\hline Variabel & $\mathbf{X}_{\mathbf{1}}$ & $\mathbf{X}_{\mathbf{2}}$ & $\mathbf{Y}$ \\
\hline Max & 9,30 & 19,00 & 3,00 \\
\hline Min & 4,00 & 7,00 & 0,00 \\
\hline Average & 6,68 & 13,73 & 0,90 \\
\hline STDEV & 1,95 & 3,07 & 0,99 \\
\hline Varian & 3,79 & 9,44 & 0,99 \\
\hline Modus & 5 & 15 & 0 \\
\hline Median & 7,25 & 14,50 & 1,00 \\
\hline
\end{tabular}

\section{Variabel Power Otot Lengan}

Hasil penelitian menunjukkan rentang skor power otot lengan $\left(\mathrm{X}_{1}\right)$ adalah antara 4.00 sampai dengan 9.30, nilai ratarata sebesar 6.68, simpangan baku sebesar 1.95, median 7.25, modus 5, varian 3.79. Kemudian data-data tersebut diubah ke Tskor, menjadi Tskor tertinggi 63.74, Tskor terendah 36.52. Distribusi frekuensi dan grafik histogram dapat dilihat dibawah ini:

Tabel 2. Distribusi Frekuensi Power Otot

\begin{tabular}{llll}
\multicolumn{4}{c}{ Lengan $\left(X_{1}\right)$} \\
\hline \multirow{2}{*}{ No } & $\begin{array}{l}\text { Interval } \\
\text { Kelas }\end{array}$ & Frekuensi & $\begin{array}{l}\text { Frekuensi } \\
\text { Relatif }\end{array}$ \\
\hline 1 & $4,00-5,77$ & 13 & $43,33 \%$ \\
\hline 2 & $5,77-7,53$ & 4 & $13,33 \%$ \\
\hline 3 & $7,53-9,30$ & 13 & $43,33 \%$ \\
\hline \multicolumn{2}{l}{ jumlah } & $\mathbf{3 0}$ & $\mathbf{1 0 0 \%}$ \\
\hline
\end{tabular}

\section{Variabel Koordinasi Mata Tangan \\ Penelitian menunjukkan rentang} skor koordinasi mata tangan $\left(\mathrm{X}_{2}\right)$ adalah antara 7 sampai dengan 19, nilai rata-rata sebesar 13.73, simpangan baku sebesar 3.07, median 14.50, modus 15 , varian 9.44. Kemudian data-data tersebut diubah ke Tskor, menjadi Tskor tertinggi 67.13, Tskor terendah 28.08. Distribusi frekuensi dan grafik histogram dapat dilihat dibawah ini:

Tabel 3. Distribusi Frekuensi Koordinasi Mata Tangan $\left(\mathrm{X}_{2}\right)$

\begin{tabular}{llll}
\hline No & $\begin{array}{l}\text { Interval } \\
\text { Kelas }\end{array}$ & Frekuensi & $\begin{array}{l}\text { Frekuensi } \\
\text { Relatif }\end{array}$ \\
\hline 1 & $7-11$ & 6 & $20 \%$ \\
\hline 2 & $11-15$ & 15 & $50 \%$ \\
\hline 3 & $15-19$ & 9 & $30 \%$ \\
\hline & jumlah & $\mathbf{3 0}$ & $\mathbf{1 0 0 \%}$ \\
\hline
\end{tabular}

\section{Variabel Akurasi Passing (Y)}

Penelitian menunjukkan rentang skor akurasi passing $(\mathrm{Y})$ adalah antara 0 sampai dengan 3, nilai rata-rata sebesar 0.90, simpangan baku sebesar 0.99 , median 1.00 , modus 0 , varian 0.99 . Kemudian datadata tersebut diubah ke Tskor, menjadi Tskor tertinggi 71.10, Tskor terendah 40.95. Distribusi frekuensi dan grafik histogram dapat dilihat dibawah ini:

Tabel 4. Distribusi Frekuensi Akurasi Passing (Y)

\begin{tabular}{llll}
\hline No & $\begin{array}{l}\text { Interval } \\
\text { Kelas }\end{array}$ & Frekuensi & $\begin{array}{l}\text { Frekuensi } \\
\text { Relatif }\end{array}$ \\
\hline 1 & $0-1$ & 21 & $70 \%$ \\
\hline 2 & $1-2$ & 7 & $23,33 \%$ \\
\hline 3 & $2-3$ & 2 & $6,67 \%$ \\
\hline & jumlah & $\mathbf{3 0}$ & $\mathbf{1 0 0 \%}$ \\
\hline
\end{tabular}

\section{PENGUJIAN HIPOTESIS}

1. Hubungan Antara Power Otot Lengan Dengan Akurasi Passing Rugby Universitas Negeri Jakarta.

Hubungan antara power otot lengan $\left(\mathrm{X}_{1}\right)$ dengan hasil akurasi passing rugby $(\mathrm{Y})$ dinyatakan oleh persamaan regresi $\mathrm{Y}=$ $70.40+0.408 \mathrm{X}_{1}$. Artinya hasil akurasi passing dapat diperkirakan dengan persamaan regresi jika variabel power otot lengan diketahui. Hubungan antara power otot lengan dengan hasil akurasi passing rugby ditunjukkan dengan koefisien korelasi $\mathrm{ry}_{1}=0.408$, koefisien korelasi tersebut harus diuji terlebih dahulu mengenai keberartiannya sebelum digunakan untuk mengambil kesimpulan. Hasil uji koefisien korelasi tersebut dapat dilihat pada tabel berikut: 
Tabel 5. Uji Keberartian Koefisien Korelasi $\mathrm{X}_{1}$ Terhadap Y

\begin{tabular}{lll}
\hline Koefisien korelasi & t.hitung & t.tabel \\
\hline 0.408 & 2.366 & 1,701 \\
\hline
\end{tabular}

Dari uji koefisien korelasi diatas terlihat bahwa $\mathrm{t}_{\text {. } \text { hitung }}=2.366$ lebih besar dari $\mathrm{t}_{\text {tabel }}=1.701$ berarti koefisien korelasinya $\mathrm{ry}_{1}=0.408$ adalah signifikan. Berdasarkan perhitungan tersebut, maka $\mathrm{H}_{0}$ ditolak dan $\mathrm{H}_{1}$ diterima yang menyatakan terdapat hubungan yang signifikan antara power otot lengan dengan akurasi passing rugby didukung oleh data penelitian. Koefisien determinasi power otot lengan dengan akurasi passing $\mathrm{ry}_{1}{ }^{2}=0.1664$ hal ini $16.64 \%$ akurasi passing dipengaruhi oleh power otot lengan.

\section{Hubungan Antara Koordinasi Mata Tangan Dengan Akurasi Passing Rugby Universitas Negeri Jakarta.}

Hubungan antara koordinasi mata tangan $\left(\mathrm{X}_{2}\right)$ dengan hasil akurasi passing rugby (Y) dinyatakan oleh persamaan regresi $\mathrm{Y}=7.025+0.859 \mathrm{X}_{2}$. Artinya hasil akurasi passing dapat diperkirakan dengan persamaan regresi jika variabel koordinasi mata tangan diketahui.

Hubungan antara koordinasi mata tangan dengan hasil akurasi passing rugby ditunjukkan dengan koefisien korelasi $\mathrm{ry}_{2}=$ 0.859 , koefisien korelasi tersebut harus diuji terlebih dahulu mengenai keberartiannya sebelum digunakan untuk mengambil kesimpulan. Hasil uji koefisien korelasi tersebut dapat dilihat pada tabel berikut:

Tabel 6. Uji Keberartian Koefisien Korelasi $\mathrm{X}_{2}$ Terhadap Y

\begin{tabular}{lll}
\hline Koefisien korelasi & t.hitung & t.tabel \\
\hline 0.859 & 8,897 & 1,701 \\
\hline
\end{tabular}

Dari uji koefisien korelasi diatas terlihat bahwa $\mathrm{t}_{\text {.hitung }}=8.897$ lebih besar dari $t_{\text {tabel }}=1.701$ berarti koefisien korelasinya $\mathrm{ry}^{2}=0.859$ adalah signifikan. Berdasarkan perhitungan tersebut, maka $\mathrm{H}_{0}$ ditolak dan $\mathrm{H}_{1}$ diterima yang menyatakan terdapat hubungan yang signifikan antara koordinasi mata tangan dengan akurasi passing rugby didukung oleh data penelitian. Koefisien determinasi koordinasi mata tangan dengan akurasi passing $\mathrm{ry}_{2}{ }^{2}=0,7378$ hal ini $73,78 \%$ akurasi passing dipengaruhi oleh koordinasi mata tangan.

3. Hubungan Secara Bersama-Sama Antara Power Otot Lengan Dan Koordinasi Mata Tangan Dengan Akurasi Passing Rugby Universitas Negeri Jakarta.

Hubungan antara power otot lengan $\left(\mathrm{X}_{1}\right)$ koordinasi mata tangan $\left(\mathrm{X}_{2}\right)$ dengan hasil akurasi passing rugby $(\mathrm{Y})$ dinyatakan oleh persamaan regresi $\mathrm{Y}=6.35+0.033 \mathrm{X}_{1}$ $+0.844 \mathrm{X}_{2}$. Sedangkan hubungan antara kedua variabel tersebut dinyatakan oleh koefisien korelasi berganda $\mathrm{ry}_{1-2}=0.899$. koefisien korelasi tersebut harus diuji terlebih dahulu mengenai keberartiannya sebelum digunakan untuk mengambil kesimpulan. Hasil uji koefisien korelasi tersebut dapat dilihat pada tabel berikut:

Tabel 7. Uji Keberartian Koefisien Korelasi $\mathrm{X}_{1-2}$ terhadap Y

\begin{tabular}{lll}
\hline Koefisien korelasi & f.hitung & f.tabel \\
\hline 0.899 & 56.93 & 3.35
\end{tabular}

Dari uji koefisien korelasi diatas terlihat bahwa $\mathrm{f}_{\text {.hitung }}=56.93$ lebih besar dari $\mathrm{f}_{\text {tabel }}=3.35$ maka koefisien korelasinya ry $_{1-2}=0.899$ adalah signifikan. Berdasarkan perhitungan tersebut, maka $\mathrm{H}_{0}$ ditolak dan $\mathrm{H}_{1}$ diterima yang menyatakan terdapat hubungan yang signifikan antara power otot lengan dan koordinasi mata tangan secara bersama-sama dengan akurasi passing rugby didukung oleh data penelitian. Koefisien determinasi power otot lengan dan koordinasi mata tangan dengan akurasi passing $\mathrm{ry}_{1-2}{ }^{2}=0.8082$ hal ini $80.82 \%$ akurasi passing dipengaruhi oleh power otot lengan dan koordinasi mata tangan.

\section{PEMBAHASAN}

Berdasarkan hasil penelitian yang dikemukakan diatas, maka hipotesis yang telah ditentukan dalam penelitian ini dapat teruji kebenarannya. Dalam arti bahwa penelitian ini mampu menjawab hipotesis penelitian yang diajukan. 
1. Hubungan antara power otot lengan dengan akurasi passing pada olahraga rugby Universitas Negeri Jakarta.

Berdasarkan dari hasil penelitian yang telah dilakukan, maka dapat ditemukan hasil penelitian pertama, terdapat hubungan yang signifikan antara power otot lengan dengan akurasi passing rugby dengan persamaan regresi $\mathrm{Y}=7.025$ $+0.859 \mathrm{X}_{2}$, koefisien korelasi $\mathrm{ry}_{1}=0.408$ dan koefisien determinasi $\mathrm{ry}_{1}{ }^{2}=0.1664$ yang berarti variabel power otot lengan memberikan sumbangan dengan hasil akurasi passing sebesar $16.64 \%$.

Berdasarkan hipotesis yang telah diuji secara statistik, terdapat hubungan yang signifikan antara power otot lengan dengan akurasi passing rugby, apabila power otot lengan pada atlit rugby baik maka hasil akurasi passing seorang atlit juga akan mendapatkan hasil yang baik begitupun sebaliknya apabila power otot lengan buruk maka hasil akurasi passing juga akan buruk.

2. Hubungan antara koordinasi mata tangan dengan akurasi passing pada olahraga rugby Universitas Negeri Jakarta.

Berdasarkan dari hasil penelitian yang telah dilakukan, maka dapat ditemukan hasil penelitian kedua, terdapat hubungan yang signifikan antara koordinasi mata tangan dengan akurasi passing rugby dengan persamaan regresi $\mathrm{Y}=7.025+$ $0.859 \mathrm{X}_{2}$, koefisien korelasi $\mathrm{ry}^{2}=0.859$ dan Koefisien determinasi $\mathrm{ry}_{2}{ }^{2}=0,7378$ yang berarti variabel koordinasi mata tangan memberikan sumbangan dengan hasil akurasi passing sebesar 73,78\%.

Begitu juga dengan koordinasi mata tangan memiliki hubungan yang berarti antara koordinasi mata tangan dengan akurasi passing rugby, apabila koordinasi mata tangan pada atlit rugby baik maka hasil akurasi passing seorang atlit juga akan mendapatkan hasil yang baik begitupun sebaliknya apabila koordinasi mata tangan buruk maka hasil akurasi passing juga akan buruk.

3. Hubungan antara power otot lengan dan koordinasi mata tangan dengan akurasi passing pada olahraga rugby Universitas Negeri Jakarta.

Berdasarkan dari hasil penelitian yang telah dilakukan, maka dapat ditemukan hasil penelitian secara bersamasama, terdapat hubungan yang signifikan antara power otot lengan dan koordinasi mata tangan secara bersama-sama dengan akurasi passing rugby dengan persamaan regresi $\mathrm{Y}=6.35+0.033 \mathrm{X}_{1}+0.844 \mathrm{X}_{2}$, koefisien korelasi $\mathrm{ry}_{1-2}=0.899$ dan Koefisien determinasi $\mathrm{ry}_{1-2}{ }^{2}=0.8082$ yang berarti variabel power otot lengan dan koordinasi mata tangan memberikan sumbangan dengan hasil akurasi passing sebesar $80.82 \%$.

$\begin{array}{ll}\text { Kedua variabel diatas hanya } \\ \text { sebagian dari faktor-faktor yang } \\ \text { mempengaruhi } & \text { akurasi passing. } \\ \text { Berdasarkan hasil penelitian hubungan }\end{array}$
Berdasarkan hasil penelitian hubungan antara power otot lengan dan koordinasi mata tangan dengan akurasi passing terdapat hubungan sebesar $80.82 \%$ ini menandakan terdapat faktor-faktor lain sebesar $19.18 \%$ yang tidak mempengaruhi akurasi passing. Dengan keterbatasan yang dimiliki peneliti berharap pada penelitian berikutnya untuk dikembangkan lebih lanjut sehingga akurasi passing rugby di Universitas Negeri Jakarta bisa terus meningkat.

\section{KESIMPULAN}

Berdasarkan hasil penelitian dan analisis data maka penelitian ini dapat disimpulkan bahwa:

1. Terdapat hubungan yang signifikan antara power otot lengan dengan akurasi passing rugby Universitas Negeri Jakarta.

2. Terdapat hubungan yang signifikan antara koordinasi mata tangan dengan akurasi passing rugby Universitas Negeri Jakarta.

3. Terdapat hubungan yang signifikan antara power otot lengan dan koordinasi mata tangan secara bersama-sama dengan akurasi passing rugby Universitas Negeri Jakarta.

\section{SARAN}

Berdasarkan pembahasan hasil penelitian dan kesimpulan sebagaimana 
yang telah dipaparkan, maka disampaikan saran-saran sebagai berikut:

1. Peneliti menyarankan agar pelatih memperhitungkan power otot lengan dan koordinasi mata tangan sebagai potensi atlit dalam menyusun program latihan.

2. Peneliti menyarankan pelatih saat memberikan program latihan, khususnya pada cabang olahraga rugby hendaknya tidak hanya memperhatikan faktor teknik tetapi juga harus memperhatikan unsur fisik yang mempengaruhi hasil akurasi passing rugby.

3. Peneliti menyarankan atlit untuk memperoleh prestasi yang optimal dalam olahraga rugby maka perlu menambah latihan-latihan yang mempengaruhi hasil akurasi passing rugby.

4. Bagi peneliti berikutnya, agar dapat melakukan penelitian terhadap hasil akurasi passing rugby dengan menambah variabel-variabel yang lain dan juga memperluas ruang lingkup penelitian.

5. Hasil penelitian ini dapat digunakan dan diaplikasikan dalam latihan, karena sesuai dengan kondisi dan kebutuhan para atlit terutama pada saat menghadapi pertandingan di tingkat Nasional maupun Internasional.

\section{DAFTAR PUSTAKA}

Harsono. Coaching Dan Aspek-Aspek Psikologis dalam Coaching, Jakarta: Departemen Pendidikan dan Kebudayaan, 1988.

International Rugby Board. Panduan Pemula Rugby Union, Ireland: International Rugby Board, 2010.

Lee Smith, Level 2 Coaching Developing Rugby Skill, Ireland: The Bridge, 2003.

Mansur M.S, Zafar Sidik, Dikdik, dkk. Materi Pelatihan Pelatih Fisik Level II. Jakarta: ASDEP Pengembangan Tenaga Dan Pembina Keolahragaan, 2009.

Matakupan, J.Teori Bermain, Jakarta: Depdikbud UT, 1992-1993.
Pyke and Rushal. Training For Sport And Fitnees, Melboune: Macmaillan Co, 1990.

Radcliffe, F.S and Farentinos, R. C.plyometric, IIlinos: Human Kinetic Publisher Inc, 1985.

R. Kirkendal, Don. Alih Bahasa M.E. Winarno, et. al. Pengukuran dan Evaluasi Untuk Guru Pendidikan Jasmani, Jakarta: P2LPTK, 1997.

Sugiyono. Metode Peneltian Pendidikan, Bandung: Alfabeta, 2015.

Thomas R Baechle and Earle Roger W. Fitnees Weight Training, terjemahan Razi Siregar, Jakarta: Raja Grapindo Persada, 2002.

Tudor O, Bompa.Theory and Methodology of Training, Lowa: Kendal Hunt Pub. Inc, 1994.

Widiastuti. Tes dan Pengukuran Olahraga, Jakarta: PT Bumi Timur Jaya, 2011. 